\title{
Incorporating jurisdiction issues into regional carbon accounts under production and consumption accounting principles
}

\author{
Karen Turner $^{1 *}$, Max Munday ${ }^{2}$, Stuart McIntyre $^{3}$ and Christa Jensen ${ }^{4}$
}

Post print (pre-proof) version of paper accepted for publication in Environment and Planning

A (published 2011, Volume 43, pp. 722-741, doi:10.1068/a43234)

1 University of Stirling, UK.

2 Cardiff University, UK.

3 University of Strathclyde, UK.

4 Regional Research Institute, West Virginia University, US.

* Corresponding author: Division of Economics, Stirling Management School, University of Stirling, Cottrell Building, Stirling, FK9 4LA, Scotland, UK; Phone: +44 (0)1786 467474; karen.turner@stir.ac.uk

\section{Acknowledgements}

The research reported in this paper has been carried out with the support of the ESRC Climate Change Leadership Fellow project "Investigating the pollution content of trade flows and the importance of environmental trade balances" (ESRC ref. RES-066-27-0029), based at the Universities of Stirling and Strathclyde. We are grateful to Randall Jackson, West Virginia University, and Kim Swales, University of Strathclyde, for their comments and advice. We are also grateful to Annette Roberts and Calvin Jones of Cardiff University for their assistance in constructing the input-output database used in this paper. 


\title{
Incorporating jurisdiction issues into regional carbon accounts under production and consumption accounting principles
}

\begin{abstract}
Despite increased public interest, policymakers have been slow to enact targets based on limiting emissions under full consumption accounting measures (such as carbon footprints). This paper argues that this may be due to the fact that policymakers in one jurisdiction do not have control over production technologies used in other jurisdictions. The paper uses a regional input-output framework and data derived on carbon dioxide emissions by industry (and households) to examine regional accountability for emissions generation. In doing so, we consider two accounting methods that permit greater accountability of regional private and public (household and government) final consumption as the main driver of regional emissions generation, while retaining focus on the local production technology and consumption decisions that fall under the jurisdiction of regional policymakers. We propose that these methods permit an attribution of emissions generation that is likely to be of more use to regional policymakers than a full global footprint analysis.
\end{abstract}

Key words: pollution attribution; jurisdiction; responsibility; input-output analysis; Wales

JEL Category: C67, Q01, R15 


\section{Incorporating jurisdiction issues into regional carbon accounts under production and consumption accounting principles}

\section{Introduction}

This paper reviews the ways in which environmental input-output frameworks can be used to examine the issue of carbon dioxide emissions attribution at the regional level. In particular the paper investigates issues of regional jurisdiction and responsibility for carbon dioxide emissions and argues that the single region environmental input-output framework can be used to provide innovative perspectives on regional responsibilities for emissions.

We argue that these perspectives are of real value in framing policy, given the need to consider issues linked to carbon dioxide emissions embodied in regional production ('smokestack') and consumption ('tailpipe') activity. The paper uses the case of Wales (a devolved region of the UK with a legal responsibility to integrate sustainable development into its policies and practices) to illustrate the approaches developed, and their potential value in better understanding some important issues of emissions dependence and attribution. In particular we show how the approaches discussed in the paper could inform policy development in terms of better understanding the regional and extra regional consequences of local consumption activity.

\section{Background and context}

There are an increasing array of emissions reduction targets that apply to the UK and its devolved administrations. Figure 1 summarises some of these key targets and aspirations. The introduction of such targets inevitably generates demands for an accounting framework that can 
accurately and practically express where responsibility for emissions lies. At one level there has been a great deal of progress in accounting for regional responsibilities through the construction of detailed carbon dioxide inventories at different geographical levels (see Munday and Roberts, 2006; Baggott et al., 2005; Digest of UK Energy Statistics, 2009). In most respects the development of these inventories has been based on a production or 'smokestack' principle focusing, for example, on where carbon dioxide emissions are actually produced, rather than focusing on how these emissions are connected to household consumption activity. Indeed, one vein of economic research on the regulation and measurement of environmental externalities has argued that there has been too much focus on the producer ('smoke-stack') as opposed to consumer generated ('tailpipe') pollution (see for example, McAusland, 2008).

A potential corollary of the above is that short term emissions targets for the UK, and regions such as Scotland and Wales, when based on a production accounting principle (PAP), could actually be achieved with ease. The structural changes that are expected to occur in these regions, coupled with stricter environmental regulations, might push out the more polluting industries. Indeed Wiedmann et al. (2008) show that in the case of the UK while domestic carbon emissions have gone down since 1990, that this has actually been offset by the growth in emissions embodied in UK imports (see also Wiedmann et al., 2010). Fundamentally, the benefits from selected production and consumption may be retained in the home economies while undesirable environmental externalities are created in other jurisdictions (see also Peters and Hertwich, 2008 for a discussion of this issue and Lenzen and Peters, 2009 for a spatial analysis of the problem at a more micro household scale). However, sustainable development objectives for the UK and its devolved regions speak strongly to a series of global responsibilities. For example, the sustainable development scheme of the Welsh Assembly 
Government stresses as a key outcome: "Living within environmental limits: by setting out a pathway to using only our fair share of the earth's resources, and becoming a One Planet nation within the lifetime of a generation" (Welsh Assembly Government, 2009, p.11).

\section{Insert Figure 1 about here}

In this context, and where sustainable development duties speak to more global responsibilities, there is value in approaches that can examine carbon dioxide emissions and other externalities based on a consumption accounting principle (CAP) and give due consideration to the responsibilities of households (Munksgaard and Pedersen, 2001; Turner et al., 2007, and see also Peters 2008 for a recent discussion of the strengths and weaknesses of production and consumption based approaches to national emissions inventories).

For the devolved administrations of the UK, the general jurisdiction and responsibility issues associated with 'production' and 'consumption' approaches to accounting for environmental externalities have not been ignored. 'Footprint' style approaches are purported to provide insights into how regional consumption activities are linked to global environmental consequences. For example Wiedmann and Minx (2007) cite a series of footprint type studies and stress the need for a proper carbon footprint definition in this context ${ }^{1}$. Wiedmann (2009) reviews the development of the carbon footprint and practical estimation approaches particularly using input-output tables as a construction framework. This also reveals that the UK government has funded estimates of the UK carbon footprint and is giving more attention to how these estimates can be practically used (see also for example, Wiedmann et al., 2007; and Minx et al, 2009 for a review of research in the UK (and elsewhere) that develops national, sub national and regional footprints ). Moreover, and in a related vein, the ecological footprint has gained

\footnotetext{
1 "The carbon footprint is a measure of the exclusive total amount of carbon dioxide emissions that is directly and indirectly caused by an activity or is accumulated over the life stages of a product". Wiedmann and Minx, 2007, p4.
} 
currency internationally as a means of connecting local consumption behaviours to a global land area needed to support that consumption behaviour. Ecological footprint studies for the UK regions have demonstrated that in regard to a 'fair earth share', consumption patterns are clearly unsustainable (see for example Moffatt et al., 2001; Ravetz et al., 2007). Indeed in the Welsh case considered in this paper the ecological footprint has been adopted as a headline indicator of sustainable development (Welsh Assembly Government, 2010a).

More generally the concept of a consumption 'footprint' at different spatial scales requires an exploration of the pollution content of trade flows. For example, Peters and Hertwich (2008) demonstrate how the flow of pollution via international trade can work to deprecate the impacts of domestic environmental policies. They estimate some 5.3 giga tonnes of carbon dioxide embodied in global trade flows in 2001. While a consumption accounting approach is conceptually appealing, there are a series of difficulties in moving towards such an analysis, particularly at the sub-national level. For example, in the devolved administrations of Scotland and Wales there have been aspirations to better establish a consumption based measure, but it is acknowledged that the trade data available to inform such an approach are limited. The lack of regional trade data further limits our knowledge of the pollution that is created to produce the goods and services being imported into and consumed within regional boundaries.

We argue in this paper that an approach grounded in a single region environmental inputoutput framework is a useful means of exploring the attribution, technical and jurisdictional issues connected to better accounting for the environmental externalities associated with regional consumption. To illustrate the analysis the focus is on Wales, one of the devolved regions of the UK. This is an interesting reference region. The Welsh Assembly Government, committed, following the Government of Wales Act in 1998 to promote sustainable development in the 
exercise of its functions, this providing an overarching framework for all of the Assembly's work. An element of the legal duty encompasses the development of sustainable development targets, and development of indicators to assist in the evaluation of activities and policy. In this respect the Welsh Assembly Government regularly reports carbon dioxide emissions as one of its headline indicators of progress towards a series of sustainable development objectives (see for example, Welsh Assembly Government, 2010b).

Interest in better understanding the attribution of carbon dioxide emissions in Wales is also contextualised by its relatively high per capita carbon dioxide emissions. For example, in 2007 of the 46 countries that signed up to the UN Framework Convention on Climate Change, Wales was ranked 6th highest in terms of carbon dioxide emissions (13.1 tonnes of carbon dioxide equivalent per capita, see National Assembly for Wales, 2009). Undoubtedly the regional industrial structure can be closely associated with this. For example, in 2007 around $30 \%$ of carbon dioxide emissions derived from just 4 sites (and with much of this generated from the large Port Talbot steelworks and the Chevron oil refinery in Pembrokeshire).

We find in this paper that a large proportion of these carbon dioxide emissions are produced to serve export demands, and that more conventional means of accounting for this pollution place inadequate emphasis on regional consumption as a pollution driver. This is important because elements of regional interventions in achieving sustainable development objectives have been aimed at changing consumption and household behaviors relating to travel, reducing use of natural resources, and purchasing more food from local producers (Welsh Assembly Government, 2009). However, the evidence base linking regional consumption behaviour to carbon dioxide emissions at region, national and international level is underdeveloped because of the paucity of data on the pollution content of trade flows. 
This paper represents an important first step for Wales (and other small open regions) in developing information that can be used in practical terms by policymakers to contrast production and consumption approaches and how these can be used to monitor progress against stated sustainable development targets. Currently there are few indicators in Wales that treat explicitly with the consumption perspectives in spite of the stated aim of the Assembly Government to contribute to sustainable development at a global level as well as a local level. Importantly there is the opportunity to use the regional input-output framework and without recourse to the large amounts of estimated data which would be needed in a more complex approach, for example, a multi-regional input-output analysis (see also Andrew et al, 2009).

We therefore discuss whether approaches developed using a single region environmental inputoutput framework provide innovative ways of examining the attribution of emissions to regional consumption. The perspectives discussed in the paper may be helpful in shedding new light on regional progress towards emissions reduction targets, and provide information that can be used by the policy community in shaping effective interventions. We believe this is important because questions of the attribution of carbon dioxide emissions are also connected to questions of how we understand the jurisdiction of devolved administrations on sustainability issues. This also links to existing work that has examined how the way in which we account for the carbon embodied in trade might impact on participation in meeting global initiatives such as the Kyoto Protocols. In the conclusions we argue that our understanding of regional jurisdiction matters in the implementation of environmental policies. Furthermore the impact of interventions critically depends on who ultimately is understood to be generating pollution, be it producers or consumers or indeed some combination of the two (see also McAusland, 2008; Gallego and Lenzen, 2005). 
The remainder of this paper is structured as follows. The third section considers the general issue of emissions attribution within the environmental input-output framework. Using the case of Wales we demonstrate how the environmental input-output system can be used to explore attribution on a production accounting principle. Here the focus is on more conventional approaches to identifying industries that are connected to relatively high levels of carbon dioxide emissions, both directly and then indirectly through emissions created in respective supply chains.

In the fourth section of the paper we demonstrate, again using Wales as a case, two more innovative approaches for examining emissions using the environmental input-output system. These approaches provide useful insights into the question of attribution. The first is the trade endogenised linear attribution system (TELAS). The second is an approach using a domestic technology assumption (DTA) to extra-regional trade. In both cases insights are provided into how regional consumption behaviour drives carbon-dioxide emissions. The section explores the practical issues in both attribution methods, and discusses the perspectives offered by the approaches, and then also considers the construction of a shared responsibility approach between consumers and producers in a region. The sixth section concludes and argues that an approach using a domestic technology assumption might be a particularly useful means through which to understand jurisdictional issues, and considers the challenges for using consumption accounting approaches to develop and inform policy interventions.

\section{Examining carbon attribution in a basic input output framework}

The Welsh analytical input-output tables form the basis for the attribution analysis (see WERU, 2007). The input-output tables for 2003 provide information on the sales and purchases of 74 
defined sectors. Also available are a symmetrical domestic use matrix and an imports matrix, the latter revealing the imports of commodity inputs produced in the rest of the UK and the rest of the world going to these same sectors, and to final consumers. These matrices are necessary for the estimation of more complex attributions of carbon emissions discussed later. ${ }^{2}$

While carbon dioxide (as carbon) generation data for Wales are currently available for 2007 and 2008, the input-output framework used means that an older industry emissions dataset is used in this paper. Data on the emissions generation (carbon dioxide as carbon, and in terms of global warming potential) for 91 defined industries for Wales were derived from information collected as part of the REWARD project (Regional and Welsh Appraisal of Resource Productivity and Development, see REWARD, 2000). This dataset also reported carbon dioxide emissions generation associated with the domestic household sector (divided into travel and nontravel related emissions). This information was aggregated into the 74 defined industries plus household final demand expenditure within the Welsh input-output framework (see below). This provides a means of estimating emissions generation per $£$ m of industry gross outputs for 2003 (the base year for the input-output framework used). ${ }^{3}$

Here we apply Leontief's (1970) basic demand driven input-output accounting framework extended for pollution generation in production and final consumption to report total carbon

\footnotetext{
${ }^{2}$ We accept that there is an issue about the accuracy of input-output tables in describing inter-industry transactions, and in particular problems relating to uncertainty over industry technical coefficients partly linked to the aggregation schemes adopted in published tables. In this paper we do not consider the impacts of uncertainty in the underlying input-output approach. Lenzen et al., (2010) provide a recent analysis of how uncertainty in technical coefficients can be understood in the estimation of carbon footprints for the UK. In the case of the Welsh input-output framework used in this paper, Beynon and Munday (2008) have examined how the impact of uncertainty in the value of technical coefficients can be assessed.

${ }^{3}$ It is accepted that this assumes that the physical relationship between output and carbon dioxide generation is fixed in the accounting year. However, in the attribution analysis in this paper we take this as an average relationship and do not seek to consider the impacts of any changes in activity.
} 
dioxide emissions generated in the region to meet total final consumption demand, $\mathrm{e}^{\mathrm{R}}$, in the following way:

$$
\mathrm{e}^{\mathrm{R}}=\boldsymbol{\varepsilon}^{\mathrm{P}}[\mathbf{I}-\mathbf{A}]^{-1} \mathbf{y}+\boldsymbol{\varepsilon}^{\mathrm{C}} \mathbf{y} *
$$

Where $\mathbf{A}$ is the inter-industry input-output matrix reported for $\mathrm{i}=\mathrm{j}=1, \ldots, \mathrm{N}$ industries and industry outputs with elements $a_{i j}$ giving the input of industry i required in per monetary unit of output $j$ and $[\mathbf{I}-\mathbf{A}]^{-1}$ is the Leontief inverse multiplier matrix with elements $b_{\mathrm{ij}}$ giving the total production of industry i required per monetary unit of final demand for output $\mathrm{j} . \boldsymbol{\varepsilon}^{\mathbf{P}}$ is a $1 \mathrm{xN}$ vector of direct output pollution coefficients (or a matrix if more than one type of emission is being analysed) with elements $\varepsilon_{\mathrm{i}}=\mathrm{e}_{\mathrm{i}} / \mathrm{x}_{\mathrm{i}}$, where $\mathrm{e}_{\mathrm{i}}$ is the physical amount of emissions directly generated by each production sector $\mathrm{i}$ in producing its output, $\mathrm{x}_{\mathrm{i}} \cdot \mathbf{y}$ is a Nx1 vector of total final demands for the output of each sector, i, with elements $\mathrm{y}_{\mathrm{i}} \cdot \boldsymbol{\varepsilon}^{\mathbf{P}}[\mathbf{I}-\mathbf{A}]^{-1}$ is a $1 \mathrm{xN}$ vector of outputpollution multipliers for each industry output $\mathrm{j}$, with elements $\kappa_{\mathrm{j}}$, which give us the total physical amount of emissions generated in production (across all $\mathrm{N}$ production sectors) to meet one unit of final demand for sectoral output $\mathrm{j}$. There are $\mathrm{z}=1, \ldots \mathrm{Z}$ final consumption groups. Where carbon dioxide emissions are directly generated by final consumers (e.g. households), one defines $\boldsymbol{\varepsilon}^{\mathrm{C}}$ as a $1 \mathrm{xZ}$ vector of direct final expenditure-pollution coefficients with elements $\varepsilon_{z}=e_{z} / y_{z}$, where $e_{z}$ is the physical amount of emissions generated by each final consumption group $\mathrm{z}$ in consuming goods and services in the process of its total final expenditure, $\mathrm{y}_{\mathrm{z}}$. The $\mathrm{Zx} 1$ vector of total final expenditures for each type of final consumption group (column totals from the input-output tables) is distinguished from the $\mathrm{Nx} 1$ vector, $\mathbf{y}$, as $\mathbf{y}^{*}$ (transposed and reported as a column vector). 
In the Welsh input-output tables for 2003 there are $\mathrm{N}=74$ industries and $\mathrm{Z}=6$ final consumer groups. The latter is composed of regional household and government consumption, capital formation, rest of UK/World (RUK and ROW) export demand and external tourists. Calculating (1) with these definitions of $\mathrm{N}$ and $\mathrm{Z}$ would represent the standard Type I case (Miller and Blair, 2009). The Type I case accounts for direct and indirect (backward linkage) effects by endogenising the $\mathrm{N}$ industries identified in the input-output accounts in the $\mathbf{A}$ and $[\mathbf{I}-\mathbf{A}]^{-1}$ matrices. Induced effects related to household income from employment (i.e. a Type II analysis) are not considered as this would involve removing household consumption from the exogenous final demand vector $\mathbf{y}$ that drives production and associated pollution activity. Such an approach would seem to be inconsistent with the commonly held belief that human consumption decisions lie at the heart of environmental problems.

Here, in order to focus attention on regional and external consumption demands, and given the importance of capital as an input to production, we have selected to endogenise capital formation/investment as covering depreciation/payments to capital, represented by other valueadded in the input-output accounts (see for example, McGregor et al., 2008). This is done by adding another row and column to the A matrix, where the row coefficients are given by payments to other value added divided by total inputs for each sector. The new column coefficients are given by local sectoral outputs produced to meet final consumption in the form of gross regional capital formation, divided by the total output of the (consuming) capital sector. The latter is given by total regional payments to capital or other value-added.

With no changes in final demand (which would require a modelling framework), the system in (1) provides the same figure for $\mathrm{e}^{\mathrm{R}}$ as one would get from an analysis using the direct carbon 
emissions intensities of each production and final consumption activity (total outputs for each industry, i, and final expenditure group, $\mathrm{z}$ :

$$
\mathrm{e}^{\mathrm{R}}=\boldsymbol{\varepsilon}^{\mathbf{P}} \mathbf{x}+\boldsymbol{\varepsilon}^{\mathrm{C}} \mathbf{y} \text { * }
$$

Thus, (1) attributes carbon emissions generated in the regional economy (during the single time period that the input-output accounts are reported for - usually one year) to final demands for regional outputs, rather than the production of those outputs, as in equation (2). The approach in (1) focuses on what Munksgaard and Pedersen (2001) term the "production accounting principle'. As these authors demonstrate, in a closed economy with no external trade linkages (1) would equate to an analysis under the consumption accounting principle, or a 'carbon footprint'.

However, regional economies tend to be very open economies. For Wales, calculation of equation (1) or equation (2) gives an estimated figure of $11.7 \mathrm{~m}$ tonnes of carbon dioxide (as carbon) emissions generated in the region, $\mathrm{e}^{\mathrm{R}}$. Included in the $\mathrm{y}\left(\right.$ and $\mathrm{y}^{*}$ ) vectors in the calculation of (1) are three broad sets of external demands. These are the vectors of export demands from RUK and ROW for Welsh goods and services, and external tourist demands of the domestic Y matrix in the regional input-output accounts. As shown in Figure 2, this means that a portion of Welsh domestic carbon emissions generated under the production accounting principle (equation 2) are attributed to external demands where equation (1) is used to calculate regional emissions under the consumption accounting principle. In the Welsh case shown in Figure 2, just under two thirds (64.4\%) of domestic carbon dioxide generation is attributable to external demands (exports and tourists) and should thus should be excluded from a Welsh 'carbon footprint' under the full consumption accounting principle. However, the single region input-output analysis above also fails to take 
account of the emissions that are embodied in imports, which would be added to the Welsh account in a carbon footprint calculation.

\section{Insert Figure 2 around here}

Turner et al. (2007) explain how an interregional input-output system could be used to calculate the actual carbon emissions embodied in each region's final consumption demands, allocating the carbon embodied in trade flows to end users in different regions. Such an interregional approach thus constitutes a technique by which actual carbon (or other environmental) footprints can be measured across trading regions/nations (and is increasingly being applied for this purpose - see Wiedmann et al. (2007) for a review; see also Wiedmann, 2009; Minx et al., 2009).

However, there are two practical issues involved with adopting such an approach. First, as explained by Turner et al. (2007), in the presence of extensive global trade, one is likely to effectively require a world interregional input-output framework, identifying all of the target region's direct and indirect trade partners and differences in production and carbon emitting technologies therein (see also Andrew et al., 2009).

Second, even if it were possible to identify such a database to analyse the resource requirements of final consumption in the region of interest, it would seem that there is also an issue of jurisdiction. This boils down to the fact that decisions regarding production technology and resulting resources used in the regions/countries that the target region directly or indirectly imports from, are likely to lie outwith the jurisdictional authority of government in the region whose consumption behaviour is under examination (on issues of jurisdiction see also Peters and Hertwich, 2008).

It is this second issue that is the focus of this paper. In the next section we attempt to develop the basic environmental input-output technique introduced above in such a way that allows us to focus on regional private and public (household and government) final consumption as the driver of 
pollution generation while retaining attention on the issue of regional jurisdiction.

\section{Exploring the attribution of carbon in the context of jurisdiction issues}

\section{TELAS analysis of regional consumption requirements under the production accounting principle}

The first question explored is whether the standard input-output approach in equation (1) can be adapted to focus on regional rather than total (including external) final consumption as the driver of total regional emissions under the production accounting principle, $\mathrm{e}^{\mathrm{R}}$. To this end in an analysis for another devolved region of the UK (Scotland) McGregor et al. (2008) propose an adjustment to the basic single region environmental input-output attribution technique in the form of a Trade Endogenised Linear Attribution System (TELAS). This involves endogenising trade in much the same way as we endogenise capital in the analysis above. Instead of counting external export (including tourist) demands for outputs of regional production sectors as elements of final consumption demand within the vector $\mathbf{y}$ in (1), the TELAS approach creates an additional regional production sector in the A matrix, a Trade sector that 'produces' the imports required in the economy as a whole (i.e. exports are produced for the purpose of facilitating imports). The row entries for each local (consuming) sector $\mathrm{j}$ are that sector's total imports from the external sector as a share of the total input/output of sector $\mathrm{j}$. The additional column entries are the outputs that are produced for export to the external sector via the trade sector by each local (producing) sector i, per unit of output in the Trade sector, which equates to total imports. ${ }^{4}$

\footnotetext{
${ }^{4}$ Note that, as in a Type II analysis (where household expenditures are taken as inputs and labour services as outputs), or when capital is endogenised (with capital formation/investment as inputs and other value-added/capital services as outputs) it is unlikely that total inputs to the Trade sector (exports) will equal total outputs (imports). Where exports are greater than imports, a proportion of export demand may be retained as exogenous in $\mathbf{y}$. If it is not, the exporting country is effectively providing a free good to the importing ones. On the other hand, where imports are greater than exports, the rest of the world is partly supporting imports to consumption in the local
} 
When equation (1) is calculated with trade endogenised, each individual (production or consumption) sector that imports from the external sector is attributed the carbon dioxide emissions embodied in the share of total domestic export production required to finance these imports (i.e. one monetary unit of imports is attributed the carbon embodied in the average monetary unit of exports required to finance these imports). In summary, the motivation for selecting the TELAS approach is to consider the fuller (economic and environmental) resource implications of export production to facilitate regional consumption requirements through trade.

The results of calculating equation (1) under the TELAS approach for the case example of Wales are given in the second column of Table 1 (the Type I results, with capital endogenous, are tabulated in the first column). The key point to note is that the total carbon dioxide emissions attributed under TELAS (shown in the first row) are the same as in the Type I case above. That is, $\mathrm{e}^{\mathrm{R}}=11.7 \mathrm{~m}$ tonnes of carbon (Welsh domestic carbon emissions under the production accounting principle) in both cases. However, with trade endogenised, all of these emissions are now attributable to regional private and public (household and government) final consumption demands. That is, the two thirds of carbon emissions that were attributable to external demands in the Type I analysis are still produced. However, under TELAS these are attributed to the imports required to (directly or indirectly) meet local consumption demands (with the reallocation to local demands reflecting the import profile of the local outputs consumed).

\section{Insert Table 1 around here}

Thus, TELAS retains focus on the generation of pollution within the region, but allows us to consider the import and export requirements of the regional economy, and the implied domestic pollution requirements therein of different types of consumption (private or public, or any

economy. To examine the nature of the balance of trade through a region's current and capital accounts, McGregor et al. (2008) demonstrate that it would be necessary to extend the analysis to a social accounting matrix (SAM). 
disaggregation therein - e.g. household consumption may be split to identify different income or other socio-economic groupings).

One policy implication that may be inferred from analysing the Type I and TELAS results alongside one another is that there is a need for Wales to export and import less, and adjust local consumption patterns in order to maintain total consumption levels. Currently, for example, there has been a drive in the region to use more locally produced food products to displace imports (Morgan and Morley, 2006). Alternatively, imports may remain constant, but the structure and type of export production required to finance these imports would have to change (so that the full local resource cost of imports as reflected in an average unit of export production is lowered). Use of the basic Type I input-output framework in the last section augmented with the TELAS analysis introduced above allows detailed analysis of the structure of pollution problems from this perspective.

\section{Insert Figure 3 around here}

For example, Figure 3 shows the composition of the carbon emissions embodied in Welsh exports from the Type I case. Here we see that just 8 of the 74 sectors identified in the Welsh input-output tables account for $93.5 \%$ of the total exported emissions in Wales, with exports of electricity generation and supply and iron and steel production being key drivers of Welsh carbon emissions in 2003. Moreover, Figure 4 shows that emissions embodied in exports from these sectors were largely supported by demand from the rest of the UK. This is particularly the case with electricity exports. In this respect, it may be useful to conduct separate analyses for the RUK and ROW cases, given that Wales is a devolved region of the UK and that binding agreements such as those under the Kyoto Protocol apply at the national level. As argued by McGregor et al (2008), if electricity can be generated using less polluting technology at the 
regional level, it may be better for the national economy as a whole if production is located there. Interestingly, in this respect, new wind capacity is expected to grow exponentially in Wales in the short term. By the end of 2006, Wales had an installed capacity of about 300MW of onshore wind. Regional planning policy guidance issued in 2005 linked to the Welsh Assembly Government's energy policies, sought $800 \mathrm{MW}$ of additional onshore wind capacity by 2010 , and with higher renewable energy targets in prospect for 2020 (Welsh Assembly Government, 2005). More generally, the location of polluting activities in the national interest would seem to be an important, but not previously (or explicitly) considered, issue in the context of the UK devolution settlement.

\section{Insert Figure 4 around here}

In extending the conventional Type I analysis with TELAS, perhaps the most useful tool is the output-pollution multipliers. Each element $\kappa_{\mathrm{j}}$ of the TELAS variant of the $\boldsymbol{\varepsilon}^{\mathbf{P}}[\mathbf{I}-\mathbf{A}]^{-1}$ vector in equation (1) gives us the total physical amount of carbon dioxide emissions generated in production (across all production sectors) to meet one unit of final demand for sectoral output $\mathrm{j}$. For example, Figure 5 shows the TELAS multipliers for six Welsh production sectors which have relatively low direct and indirect carbon dioxide emissions-intensities (the latter reported in the standard Type I output-carbon dioxide multipliers). The large difference between the Type I and TELAS output-emissions intensities of these sectors reflects their import intensity, which (under the TELAS perspective that export production is necessary to facilitate imports) implies that there will be relatively large carbon dioxide emissions impacts throughout the economy should activity in these sectors expand (though note that all have a lower TELAS carbon dioxide multiplier than the average unit of exports in the Welsh economy, reflected in the 'Trade' sector multiplier). Given that the six sectors identified in Figure 5 would not generally be regarded as 
'important' sectors in terms of their conventional pollution profile, what the TELAS analysis does is focus attention on the importance of import dependence in the Welsh economy, and the likely emissions implications and wider resource requirements of financing these imports.

\section{Insert Figure 5 around here}

Note, however, that in the case of Wales in 2003 , the value of imports ( $£ 36.5 \mathrm{bn}$ ) was greater than the value of exports ( $£ 30 \mathrm{bn})$. That is, in financial terms, Welsh imports of goods and services were partly supported by the external (rest of UK and rest of the world) sector. TELAS multipliers are therefore likely to be understated and policymakers may wish to consider the impacts of increased export production to finance import demand. ${ }^{5}$

In more general terms, a key point to note is that under TELAS no attempt is made to estimate the carbon emissions generated in other regions/countries in producing the commodities that are imported (i.e. the carbon embodied in imports). In other words, TELAS does not address carbon emissions generated outside the target region to support local consumption. Instead it focuses on carbon emissions generated within the target region to support regional consumption (i.e. regional emissions under the production accounting principle). As explained by McGregor et al., (2008) in proposing the TELAS approach the underlying philosophy is basically a neo-classical resource-constrained view of the open economy where the essential purpose of export production is to finance the imports required to fulfil local consumption demands.

However, on the other hand, there is increasing public concern over the global impacts of human consumption decisions. This has led to increasing focus on 'footprint' measures, which

\footnotetext{
${ }^{5}$ It is important to note that in all cases examined here a modeling framework would be required to analyse the impacts of changes in activity, for example how shifts in activity to increase export production may be achieved, and what their implications would be. While input-output is an entirely appropriate framework for accounting for the structure of pollution problems (as we do here), it is only a very special and limited case of general equilibrium modeling, and likely to be too restrictive to analyse the impacts of such shifts in economic structure, and how they may be achieved.
} 
require consideration of emissions embodied in imports (not considered as part of the TELAS analysis above). Despite this fact, policymakers have been slow to enact firm targets based on limiting emissions under full consumption accounting measures, such as carbon footprints. It is our speculation that this may reflect the fact that policymakers in any one jurisdiction do not have control over technologies used in other jurisdictions. Therefore, we propose a second adjustment to the basic single region input-output attribution technique that does attempt to take account of the pollution content of imports, but retains focus on the jurisdictional limits to the authority of regional policymakers.

\section{DTA analysis of regional consumption requirements under a limited application of the}

\section{consumption accounting principle}

The attribution technique that we consider next involves adopting what is referred to as the ‘domestic technology assumption' (see also Druckman and Jackson, 2009). This involves assessing the pollution content of the combined (total) use of commodities (regional and imported) according to the domestic pollution technology in the $\mathbf{E}^{\mathbf{P}}$ vector in equations (1) and (2) for the target economy. In previous studies the 'domestic technology assumption' has been regarded as a necessary assumption to fill data gaps regarding the pollution profile of production in other regions/countries (see Andrew et al., 2009). Here we propose that it may be a useful assumption in the context of the issue of production being located outwith the jurisdictional authority of policymakers in the consuming region. We may think of the approach in terms of the pollution implications if the region of study (here, Wales) were to produce the commodities it chooses to consume itself. We apply the 'domestic technology assumption' to a variant of the $\mathbf{A}$ matrix that records the combined use of (regional and imported) intermediate inputs to 
production. In this respect, the DTA approach requires slightly more data in input-output format (an imports matrix), but it retains a focus on intermediate and final consumption in the target economy without extending to a full interregional analysis at this stage. The $[\mathbf{I}-\mathbf{A}]^{-1}$ matrix then gives the (hypothetical) global multiplier effects for the portion of the global economy that serves regional consumption. The $\mathbf{\varepsilon}^{\mathbf{P}}[\mathbf{I}-\mathbf{A}]^{\mathbf{1}}$ multiplier vector gives the global output-carbon multiplier effects if each external sector i shared the emissions characteristics of the corresponding sector $\mathrm{i}$ in the target region. Thus, the total carbon implications of regional final consumption, $\mathrm{e}^{\mathrm{T}}$, are estimated under the domestic technology assumption (hereafter DTA) as:

$$
\mathrm{e}^{\mathrm{T}}=\boldsymbol{\varepsilon}^{\mathbf{P}}[\mathbf{I}-(\mathbf{R}+\mathbf{M})]^{-1}\left(\mathbf{y}^{\mathbf{R}}+\mathbf{y}^{\mathbf{M}}\right)+\boldsymbol{\varepsilon}^{\mathbf{C}} \mathbf{y} *
$$

Where the domestic intermediate matrix in (1) is relabelled $\mathbf{R}$ and $\mathbf{M}$ is the $(\mathrm{N}+1) \mathrm{x}(\mathrm{N}+1)-$ with capital endogenised - matrix of imported intermediate inputs. Similarly, $\mathbf{y}^{\mathbf{R}}$ corresponds to $\mathbf{y}$ in (1) while $\mathbf{y}^{\mathbf{M}}$ gives us imports to exogenous final consumption by commodity/external sector output (note that in our empirical analyses we identify $\mathrm{M}$ matrices and $\mathrm{y}^{\mathrm{M}}$ vectors distinguishing between imports from the rest of the UK and the rest of the world, the regions for which data in input-output format are currently available for Wales). Note that, as we include imports, export demands simultaneously drop out of the final demand vectors - i.e. we focus our attention on local (regional) final consumption demands.

Here, we apply the approach in equation (3) to examine the carbon dioxide emissions attributable to final consumption demand in Wales (for 2003). Again, as in the analyses above, we endogenise capital in order to focus on regional private and public (household and government) final consumption demands. 
The final column of Table 1 shows the results of calculating equation (3) to give us attribution to local final consumption demands under the DTA assumption. Here, note that while the allocation between regional household and government consumption is broadly similar to that in the TELAS case (second column), the total amount being attributed, $\mathrm{e}^{\mathrm{T}},(11.4$ million tonnes) is less than the actual carbon emissions generated in Wales in $2003, \mathrm{e}^{\mathrm{R}},(11.7$ million tonnes) in equations (1) and (2). This suggests that the carbon dioxide emissions embodied in Welsh imports (under DTA) are less than the emissions embodied in exports. More detailed examination of the DTA results relative to the conventional Type I results from Section 2 demonstrate this point. Table 2 shows that domestic (Welsh) emissions generation supported by households and government is the same under both measures. However, while the Type I analysis in column one gives us the actual carbon dioxide emissions generation supported by external demands (7.6 million tonnes, just under two thirds of actual carbon dioxide emissions generated in Wales in 2003), we require the DTA analysis to get even an estimated measure of the emissions embodied in imports. Combined use of the results from the standard Type I analysis above and the DTA analysis here also allows us to examine the components of the implied carbon trade balance. That is, while the final column of Table 1 provides PAP emissions attributable to export demands, the final column of Table 2 shows the DTA CAP results. Here we are able to identify the emissions embodied in direct imports to Welsh households and government (final consumption vector $\mathbf{y}^{\mathbf{M}}$ in equation (3)) and also indirect emissions embodied in imports to Welsh production (matrix $\mathbf{M}$ ) to meet Welsh final consumption for regional outputs (vector $\mathbf{y}^{\mathbf{R}}$ ), though all are ultimately attributable to Welsh household and government final consumption in Table 2. As in the PAP analysis reported in the first column of Table 1, we also distinguish between carbon embodied in imports from the rest of the UK and the rest of the 
world. At an aggregate level, carbon embodied in imports breaks down into just under 6million tonnes supported by household consumption and a further 1.2 millions supported by government consumption.

However, the more interesting breakdown is that the largest share of carbon embodied in imports, 4.9million tonnes $(67.7 \%)$, is associated with imports from the rest of the world, which is in contrast with the export side of the 'carbon trade balance', where (excluding tourists) just 2million tonnes of carbon are embodied. On the other hand, while (again excluding tourists) Welsh exports to the rest of the UK embody 5.4million tonnes of carbon (46.2\% of total Welsh pollution generation under PAP), the level of carbon embodied in imports from the rest of the UK is considerably lower, at 2.3 million tonnes. This leads to Wales running a carbon trade surplus with the rest of the UK which, at 3.1million tonnes, is sufficient to offset the carbon deficit with the rest of the world (2.9million tonnes). Referring back to Figure 4, this outcome reflects the fact that exports to the rest of the UK dominate in all but one of the 8 sectors with the highest $\mathrm{CO} 2$ generation to meet export demand.

\section{Insert Table 2 around here}

Thus, the key result of the DTA analysis for Wales (2003) is that of a net 'carbon trade surplus' (i.e. emissions embodied in exports are greater than those embodied in imports), though the results in Table 2 demonstrate that this is driven by the relationship with the rest of the UK. This raises several issues. First, this 'regional carbon footprint' of regional consumption demands is unlikely to equal the actual global carbon footprint of Welsh consumption as we would expect production technologies to differ from those that apply in Wales. That is, the import results in Table 2 will be sensitive to the assumptions regarding production technology associated with imports. However, Welsh policymakers do not have any jurisdiction over the 
latter, with the implication that the hypothetical measure reported in the final column of Table 1 and in Table 2 may be of more practical use at the local level (although, in the context of trade with the rest of the UK, of which Wales is a devolved region, this issue must constitute an important, but previously neglected, part of the devolution package).

This raises a second issue. In the Welsh example here, in focussing on technologies over which local policymakers have jurisdiction, we get the result that the region is effectively 'exporting sustainability' despite the fact that (at least in the accounting year of 2003) it runs a trade deficit. This may be regarded as a 'good' footprint result. However, the problem in the current policy configuration (where emissions targets tend to be set in terms of the production accounting principle) is that upward pressure is being put on Welsh domestic carbon dioxide emissions generation by consumption demands in the rest of the UK and internationally. On the other hand, one may also argue that Wales benefits (in economic terms at least) from production to meet export demands. For example, at the time of writing, the Port Talbot steelworks (part of the Iron and Steel sector identified here, which alone contributes 30.5\% of carbon embodied in exports - see Figure 3) is investing in a new furnace to allow expansion of productive capacity. This investment (albeit by a foreign-owned firm - Tata of India) would surely not take place if it were not in the economic interest of Wales.

This raises the question as to whether the basic consideration of PAP and CAP that is the focus of much policy debate should be augmented with fuller information to consider whether some shared responsibility criterion would be appropriate. In this respect Peters (2008, p.14) points out that some authors highlight that production accounting and consumption based approach "represent two extremes and it is beneficial to share responsibility between the producer and the consumer". The issue of how economic benefit may impact on carbon 
measures is addressed in a literature that focuses on the development of a shared responsibility measure (for example, Gallego and Lenzen, 2005; Lenzen et al., 2007; Andrew and Forgie, 2008; Lennox and Andrew, 2006; Zhou, 2009). For example, Lenzen et al., (2007) suggest that a share of responsibility should be retained by producers based on the value added contribution of output. There might be value in applying existing techniques developed by the authors above to the case of Wales. However, we believe that the jurisdictional focus of the DTA analysis presented here may be extended to contribute to the shared responsibility debate by considering the relaxation of the DTA assumption. That is, we have argued that the DTA approach allows regional policymakers to focus on consumption and technology decisions that are under their jurisdiction; then any increase in the consumption accounting measure from relaxing the DTA assumption may be retained by the countries that imports are sourced from. Exploring this possibility further is a focus of our continued research in this area.

\section{Discussion and conclusions}

The paper has examined how a regional environmental input-output system can be used to derive estimates of the carbon dioxide emissions connected with regional consumption patterns. One context of the paper was that much of the regional reporting of carbon dioxide emissions and other externalities is undertaken on a production accounting principle basis. At one level the monitoring of point sources of emissions is critical for regulatory purposes and fulfils obligations that the UK has towards international treaties on emissions reduction. Moreover, monitoring point sources is also a means for policymakers to target interventions on heavily polluting sectors, albeit with limits on how far a devolved government can mitigate emissions even within their own jurisdiction. However the paper also argued that the sustainable development duties 
being faced by devolved regions in the UK speak to global as well as local responsibilities, which implies a requirement to understand how regional consumption patterns create externalities outside regional boundaries. While there has been a growing focus on footprint style measures, it was argued that the paucity of data on regional trade and the pollution content of this trade set limits on what can be achieved. Moreover, policymakers may be reluctant to set targets for measures that are influenced by factors outwith their jurisdictional authority.

The importance of making firm connections between regional consumption and environmental effects is also highlighted in the nature of regional interventions to meet with a broad range of sustainable development objectives. For example, in the Welsh case examined in this paper, the future achievement of sustainable development objectives is expected to focus on the promotion of consumer behaviour change (Welsh Assembly Government, 2009). Furthermore, the development of consumption based approaches will be important as structural change in Wales, and the continued loss of more polluting manufacturing and energy sectors means that the pollution embodied in imports could trend upwards as is evident in the overall UK case (Wiedmann et al., 2008).

Where regional consumption is recognised as the key determinant of emissions generation and a focus of attribution, then measures like TELAS and DTA allow the region to 'take responsibility' for supported emissions, but within a framework over which they have jurisdiction, i.e. those regional consumption demands and technologies which support these emissions. Moreover, the DTA approach shares the basic feature of McGregor et al., (2008) TELAS and more basic environmental input-output attribution techniques (Miller and Blair, 2009) in that it uses currently available data at the regional level. The corollary is a transparent but rigorous 'first step' that the policy community may feel at ease with (particularly where 
single region multiplier analyses have been routinely been used for economic impact analysis). A full consumption accounting would require an inter-regional and international input-output framework. However, in the TELAS and DTA analysis there was no need for the considerable amounts of economic, trade, and emissions data from regional and national economies that are linked to the relatively open Welsh economy through trade. Indeed, we surmise that few UK regions have access to the resources and expertise which would make the estimation of a full carbon footprint possible.

More generally the techniques investigated in this paper also provide a useful basis for scenario analysis. For example, as the case region faces a prolonged period of structural change the approaches lay a foundation for an analysis of how resulting changes in consumption induced trading patterns may affect the levels of associated emissions. However, such a scenario analysis is likely to require relaxation of some of the restrictive assumptions of the input-output model in a more flexible general equilibrium framework.

Set against the above are a series of issues that need to be stressed. The use of the techniques is not without difficulty and all approaches grounded in an input-output framework will be subject to its general limitations (see Miller and Blair, 2009 for a review of these limits, and Lenzen et al., 2010 on issues surrounding uncertainty in input-output frameworks). Moreover, at a practical level not all of the UK regions have input-output data published in a format that would enable the analysis undertaken in this paper. This situation continually improves and with the additional possibility of deriving regional tables from the UK input-output framework where regional tables do not exist.

We accept that in the TELAS and DTA cases presented here no account is taken of the actual emissions content of regional imports. We justify this on the basis of the limited jurisdiction of 
regional authorities. Nonetheless it is accepted that the DTA and TELAS approaches move one only part way to a full accounting of the environmental externalities associated with regional consumption. However, where data on the country/region source of imports and associated carbon intensities do become available it is important to note that the DTA assumption can be relaxed. This would involve replacing the regional pollution intensity vector with one reflecting the actual pollution of imports used. In this respect the authors are currently collaborating with colleagues in the OECD to identify data to make this step. Indeed, as argued at the end of the previous section, the difference in results between the DTA and relaxed DTA versions of the CAP measure may inform a shared responsibility criterion.

In a practical policy context, even if data on the pollution profile of industries that export to the target region are available to transform the DTA model into a (uni-directional) actual footprint calculation, we propose that it would still be useful for policymakers to consider such a measure alongside the results of the DTA analysis. ${ }^{6}$ This would allow policymakers to focus on the implications of the limits to their jurisdictional authority and perhaps to consider some type of policy coordination with authorities in the exporting region. Indeed, a key point in the DTA analysis presented here is that Wales is absolved of responsibility for the technology decisions in its own production to meet export demand. From a global environmental perspective, responsibility needs to be taken for the technology decisions underlying pollution embodied in trade flows. In the context of UK devolution (where some commitments, such as those under the Kyoto Protocol, apply at the national level) there may be a case for a mixed approach that measures actual pollution embodied in interregional trade flows (i.e. trade with the rest of the UK) while retaining the DTA assumption in examining imports from the rest of the world.

\footnotetext{
${ }^{6}$ We accept the resulting method would still neglect the inter-regional feedback and source country multiplier effects that would be captured in a full inter-regional input-output system.
} 


\section{References}

Andrew R, Forgie V, 2008, "A three-perspective view of greenhouse gas emission responsibilities in New Zealand” Ecological Economics 68 194-204

Andrew R, Peters G, Lennox J, 2009 “Approximation and regional aggregation in multi-regional input-output analysis” Economic Systems Research 21 311-335

Baggott S, Brown L, Milne R, Murrells T, Passant N, Thistlethwaite G, Watterson J, 2005, UK Greenhouse Gas Inventory, 1990 to 2003, Annual Report for submission under the Framework Convention on Climate Change AEAT/ENV/R/1971 Available through http://www.naei.org.uk/report_link.php?report_id=317 accessed 20 ${ }^{\text {th }}$ May 2010

Beynon M, Munday M, 2008 "Stochastic key sector analysis using backwards and forwards linkages: An application to the regional Input-Output tables of Wales" Annals of Regional Science 42 863-877

Digest of UK Energy Statistics 2009, see http://www.decc.gov.uk/en/content/cms/statistics/publications/dukes/dukes.aspx accessed 20th May 2010.

Druckman A, Jackson T, 2009 "The carbon footprint of UK households 1990-2004: A socioeconomically disaggregated, quasi-multi-regional input-output model” Ecological Economics 68 2066-2077

Gallego B, Lenzen M, 2005, "A consistent input-output formulation of shared consumer and producer responsibility” Economic Systems Research 17 365-391

Lennox J, Andrew R, 2006, Reforming water use rights in Canterbury: a shared responsibilities perspective. Sendai, Japan, Internet site http://www.iioa.org/pdf/Intermediate2006/Full\%20paper_Lennox.pdf

Lenzen M, Peters, G, 2009, "How city dwellers affect their resource hinterland - a spatial impact study of Australian households" Journal of Industrial Ecology 14 73-90

Lenzen M, Murray J, Sack F, Wiedmann T, 2007, "Shared producer and consumer responsibility - theory and practice" Ecological Economics $6127-42$

Lenzen M, Wood R, Wiedmann T, 2010, "Uncertainty analysis for Multi-Region Input-Output models - a case study of the UK's carbon footprint” Economic Systems Research 22 43-63

Leontief W, 1970, "Environmental repercussions and the economic structure: an input-output approach" Review of Economic and Statistics 52 262-277

McAusland C, 2008, “Trade, politics and the environment: Tailpipe vs. smokestack" Journal of Environmental Economics and Management 55 52-71 
McGregor P. Swales J, Turner K, 2008, “The $\mathrm{CO}_{2}$ trade balance between Scotland and the rest of the UK: performing a multi-regional environmental input-output analysis with limited data" Ecological Economics 66 662-673

Miller R, Blair P, 2009, Input-Output Analysis: Foundations and Extensions $2^{\text {nd }}$ ed (Cambridge University Press, Cambridge)

Minx J, Wiedmann T, Wood R, Peters G, Lenzen M, Owen M, Scott K, Barrett J, Hubacek K, Baiocchi G, Paul A, Dawkins E, Briggs J, Guan D, Suh S, Ackerman F, 2009, "Input-output analysis and carbon footprinting: An overview of applications" Economic Systems Research 21 187-216

Moffatt I, Hanley N, Wilson M, 2001, Measuring and Modelling Sustainable Development (Parthenon, London)

Morgan K, Morley A, 2006, Sustainable Procurement: From Good Intentions to Good Practice, Report to the Welsh Local Government Association, Cardiff.

Munday M, Roberts A, 2006, "Developing approaches to measuring and monitoring sustainable development in Wales: A review" Regional Studies 40 535-544

Munksgaard J, Pedersen K, 2001, “ $\mathrm{CO}_{2}$ accounts for open economies: producer or consumer responsibility?” Energy Policy 29 327-334

National Assembly for Wales, 2009, Carbon Dioxide Emissions for Wales, Paper 09/037, Members Research Service, National Assembly for Wales, Cardiff

Peters G, 2008, "From production-based to consumption-based national emission inventories" Ecological Economics 65 13-23

Peters G, Hertwich E, 2008, "CO2 embodied in international trade with implications for global climate policy” Environmental Science and Technology 42 1401-1407

Ravetz J, Bond S, Meikle A, 2007, One Planet Wales: Transforming Wales for a prosperous future within our fair share of earths resources. Report for World Wildlife Fund. See www.wwf.org.uk/filelibrary/pdf/25700_wwf_report_e.pdf accessed 23rd Nov 2009

Reward, 2000, Regional and Welsh Appraisal of Resource Productivity and Development: Key Industrial Environmental Pressures - Air Emissions and Energy Use available from http://www.scpnet.org.uk/downloads/Environmental_Data/air-and-energy-167.pdf accessed last on 20th May 2010.

Turner K, Lenzen M, Wiedmann T, Barrett J, 2007, “Examining the Global Environmental Impact of Regional Consumption Activities - Part 1: A Technical Note on Combining Input-Output and 
Ecological Footprint Analysis" Ecological Economics 62 37-44

Welsh Assembly Government, 2005, Planning Policy for Wales; Technical Advice Note 8: Planning for Renewables, Planning Division, National Assembly for Wales see also Energy http://new.wales.gov.uk/docrepos/40382/4038231121/403821/403821/4038212/mipps1e.pdf?lang=en

Welsh Assembly Government, 2009, One Wales One Planet: The Sustainable Development Scheme of the Welsh Assembly Government, see http://wales.gov.uk/docs/desh/publications/090522susdevsdspage0115en.pdf last accessed 7th December 2010

Welsh Assembly Government, 2010a, State of the Environment. Indicator 2a Ecological footprint, available from http://www.statswales. wales.gov.uk/tableviewer/document.aspx?ReportId=5786 accessed $20^{\text {th }}$ May 2010.

Welsh Assembly Government, 2010b, State of the Environment. Indicator 7a Greenhouse gas emissions: see http://www.statswales. wales.gov.uk/tableviewer/document.aspx ?ReportId=5758 accessed $20^{\text {th }}$ May 2010.

WERU (Welsh Economy Research Unit), 2007, Welsh Input-Output Tables for 2003, Report for Welsh Assembly Government, and available on request from WERU, Cardiff Business School, Colum Drive, Cardiff, CF10 3EU

Wiedmann T, Lenzen M, Barrett J, Turner K, 2007, "Examining the Global Environmental Impact of Regional Consumption Activities - Part 2: Review of input-output models for the assessment of environmental impacts embodied in trade" Ecological Economics 61 15-26

Wiedmann T, 2009 "Editorial: Carbon footprint and input-output analysis: an introduction" Economic Systems Research 21 175-186

Wiedmann T, Minx J, 2007 A Definition of 'Carbon Footprint'. In: C.C. Pertsova (ed.) Ecological Economics Research Trends. http://www.isa-research.co.uk/reports.html, Nova Science Publishers, Inc. and ISA-UK, 55-65.

Wiedmann T, Wood R, Lenzen M, Minx J, Guan D, Barrett J, 2008, Development of an embedded carbon emissions indicator - Producing a time series of Input-Output tables and embedded carbon dioxide emissions for the UK using a MRIO Data Optimisation System. Report to the UK Department for Environment Food and Rural Affairs, Stockholm Environment Institute \& Centre for Integrated Sustainability Analysis at University of Sydney

Wiedmann T, Wood R, Lenzen M, Minx J, Guan D, Barrett J, 2010 "The carbon footprint of the UK - Results from a Multi-Region Input-Output model” Economic Systems Research 22 19-42. 
Zhou X, 2009, How does trade adjustment influence national inventory of open economies? Accounting embodied carbon based on multi-region input-output model. In: Institute for Global Environmental Strategies (IGES) (ed.) International Forum on Sustainable Asia and the Pacific. Shonan, Japan 
Table 1: Summary of Attribution of Total $\mathrm{CO}_{2}$ as Carbon (Tonnes) to Final Consumers in Wales (2003)

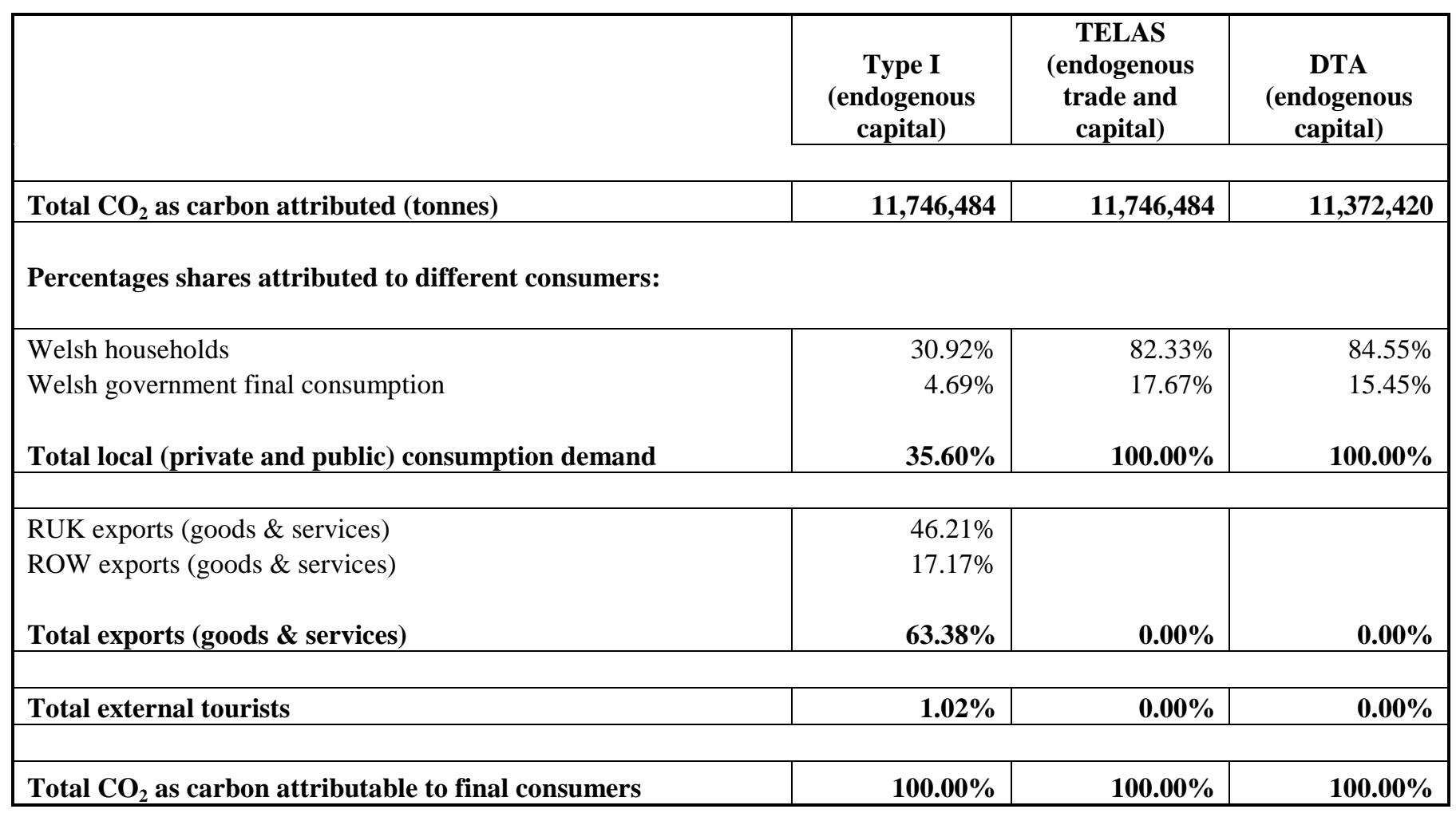


Table 2: Input-Output Accounting of the Welsh Carbon Trade

Balance (2003)

\begin{tabular}{|c|c|c|}
\hline & $\begin{array}{l}\text { Actual } \\
\text { generation } \\
\text { (Type 1) }\end{array}$ & $\begin{array}{l}\text { Hypothetical } \\
\text { generation } \\
\text { (DTA) }\end{array}$ \\
\hline Total CO2 (as carbon) attributed (tonnes) & $11,746,484$ & $11,372,420$ \\
\hline \multicolumn{3}{|l|}{ CO2 (as carbon) supported by Welsh final demands } \\
\hline \multicolumn{3}{|l|}{ Domestic (Welsh) CO2 (as carbon) generation: } \\
\hline Directly generated (households): & $2,130,600$ & $2,130,600$ \\
\hline \multicolumn{3}{|l|}{ Indirect - generated in Welsh production sectors supported by: } \\
\hline \multirow{3}{*}{$\begin{array}{r}\text { Households (incl. domestic tourism) } \\
\text { Government }\end{array}$} & $1,500,977$ & $1,500,977$ \\
\hline & 550,614 & 550,614 \\
\hline & $4,182,191$ & $4,182,191$ \\
\hline \multicolumn{3}{|l|}{ Indirect Carbon embodied in imports (hypothetical) } \\
\hline \multicolumn{3}{|l|}{ RUK } \\
\hline Households (incl domestic tourism) & & $1,866,150$ \\
\hline \multirow[t]{2}{*}{ Government } & & 456,349 \\
\hline & & $2,322,499$ \\
\hline \multicolumn{3}{|l|}{ ROW } \\
\hline Households (incl. domestic tourism) & & $4,117,988$ \\
\hline \multirow[t]{2}{*}{ Government } & & 749,742 \\
\hline & & $4,867,730$ \\
\hline Total carbon embodied in imports & & $7,190,229$ \\
\hline \multicolumn{3}{|l|}{ CO2 (as carbon) supported by external demands for Welsh production } \\
\hline \multirow{4}{*}{$\begin{array}{r}\text { Exports of goods and services RUK } \\
\text { Exports of goods and services ROW } \\
\text { External tourists }\end{array}$} & $5,428,059$ & \\
\hline & $2,016,558$ & \\
\hline & 119,676 & \\
\hline & $7,564,293$ & \\
\hline \multicolumn{3}{|l|}{ Implied CO2 (as carbon) Trade Balance (Deficit): } \\
\hline \multicolumn{3}{|l|}{$\begin{array}{r}\text { Actual CO2 (as carbon) generation minus DTA CO2 (as carbon) generation } \\
\text { (CO2 (as carbon) embodied in exports minus CO2 (as carbon) embodied in } \\
\text { imports) }\end{array}$} \\
\hline RUK & & $3,105,560$ \\
\hline ROW & & $-2,851,172$ \\
\hline Total (including external tourists) & & 374,064 \\
\hline
\end{tabular}


Figure 1: Emissions targets for the UK and Devolved Administrations

\section{UK Targets}

\begin{tabular}{|c|}
\hline Kyoto \\
Reduce the \\
basket of six \\
greenhouse \\
gases by $12.5 \%$ \\
compared to \\
1990 levels by \\
$2008-2012$ \\
\hline
\end{tabular}

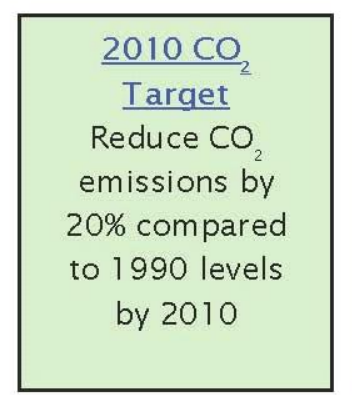

\begin{tabular}{|l|}
$\frac{2020 \mathrm{CO}_{2}}{\mathrm{e}_{2}}$ \\
$\frac{\text { Target }}{\text { Reduce } \mathrm{CO}_{2} \mathrm{e}}$ \\
emissions by \\
$34 \%$ compared \\
to 1990 levels \\
by 2020
\end{tabular}
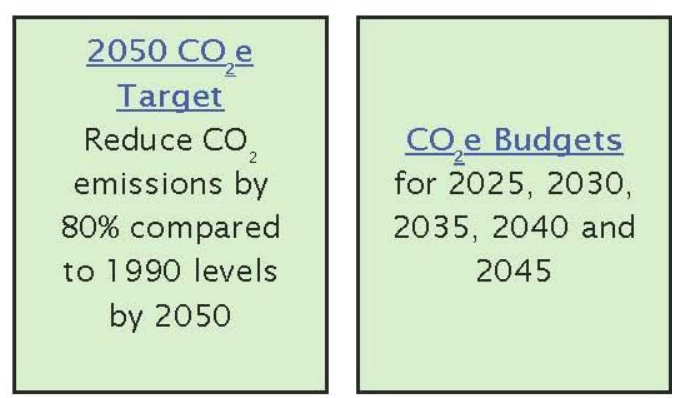

\section{Wales Targets}

\begin{tabular}{|c|}
\hline Annual Tarqets by \\
$\frac{2011}{3 \% \text { annual reduction in }}$ \\
$\mathrm{CO}_{2}$ e emissions, in \\
areas of devolved \\
competence
\end{tabular}

\begin{tabular}{|c|}
\hline$\frac{\text { Annual Sectoral }}{\text { Targets }}$ \\
Set minimum \\
contribution to $\mathrm{CO}_{2} \mathrm{e}$ \\
emission reductions \\
over a 10 year period
\end{tabular}

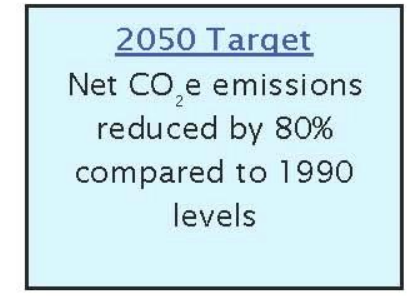

\section{Scotland Targets}

2010: Reduce $\mathrm{CO}_{2}$ below 2009 by 2010

2011-2019: Reduce $\mathrm{CO}_{2}$ e emissions to be lower than preceding year 2020: Net $\mathrm{CO}_{2}$ e emissions reduced by $42 \%$ compared to baseline 2020-2050: $\mathrm{CO}_{2}$ e emissions to be $2-3 \%$ lower than preceding year 2050: Net $\mathrm{CO}_{2}$ e emissions reduced by $80 \%$ compared to baseline

\section{Northern Ireland Targets}

2025: Reduce emissions of $\mathrm{CO}_{2}$ by $30 \%$ on baseline levels 2025: Reduce emissions of all $\mathrm{GHGs}\left(\mathrm{CO}_{2} \mathrm{e}\right)$ by $25 \%$ on baseline levels

Source: National Assembly for Wales, 2009 
Figure 2: Welsh Type I Emissions by Final Demand Category

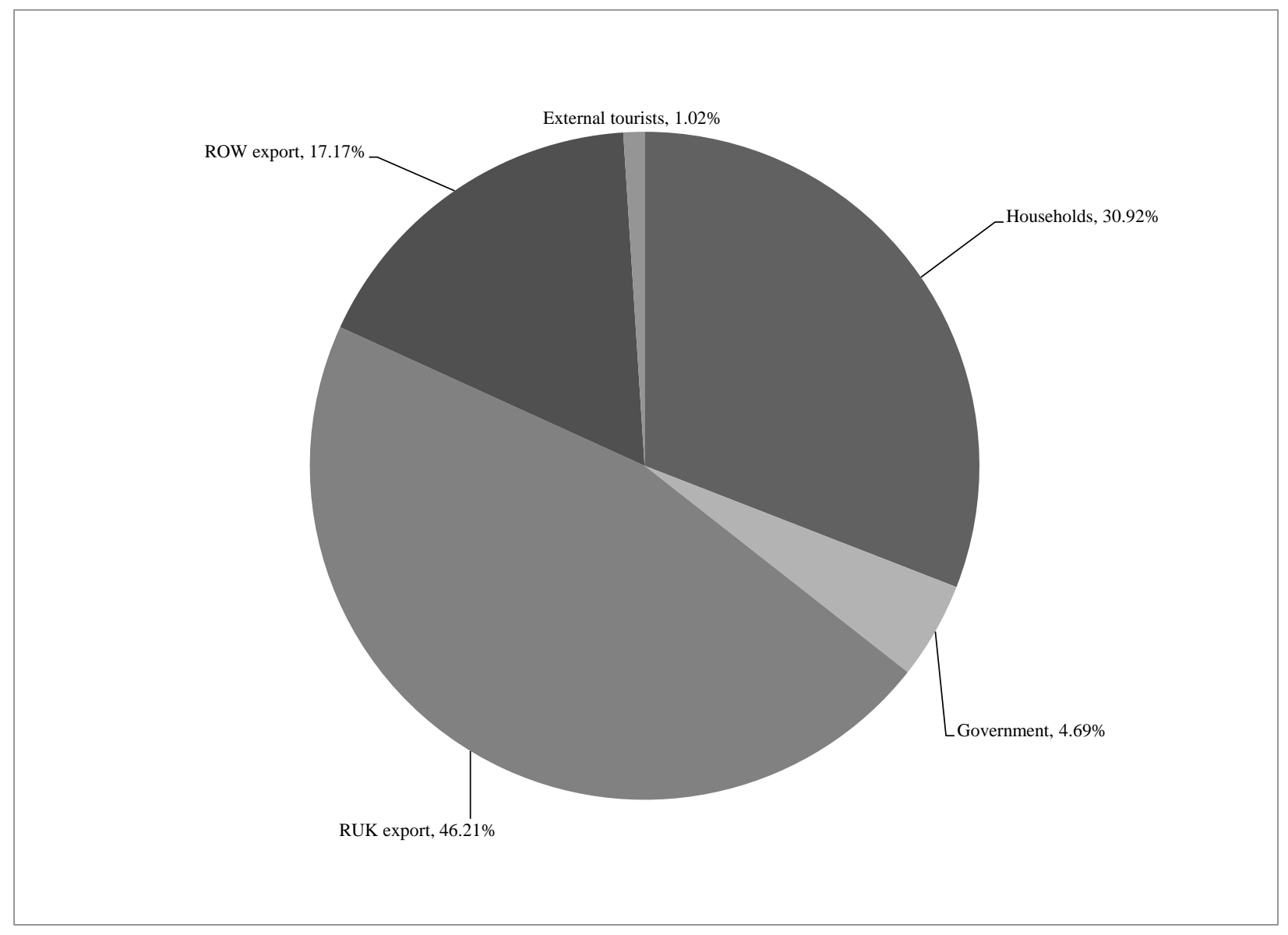


Figure 3: Composition of emissions embodied in export demand from Wales by sector

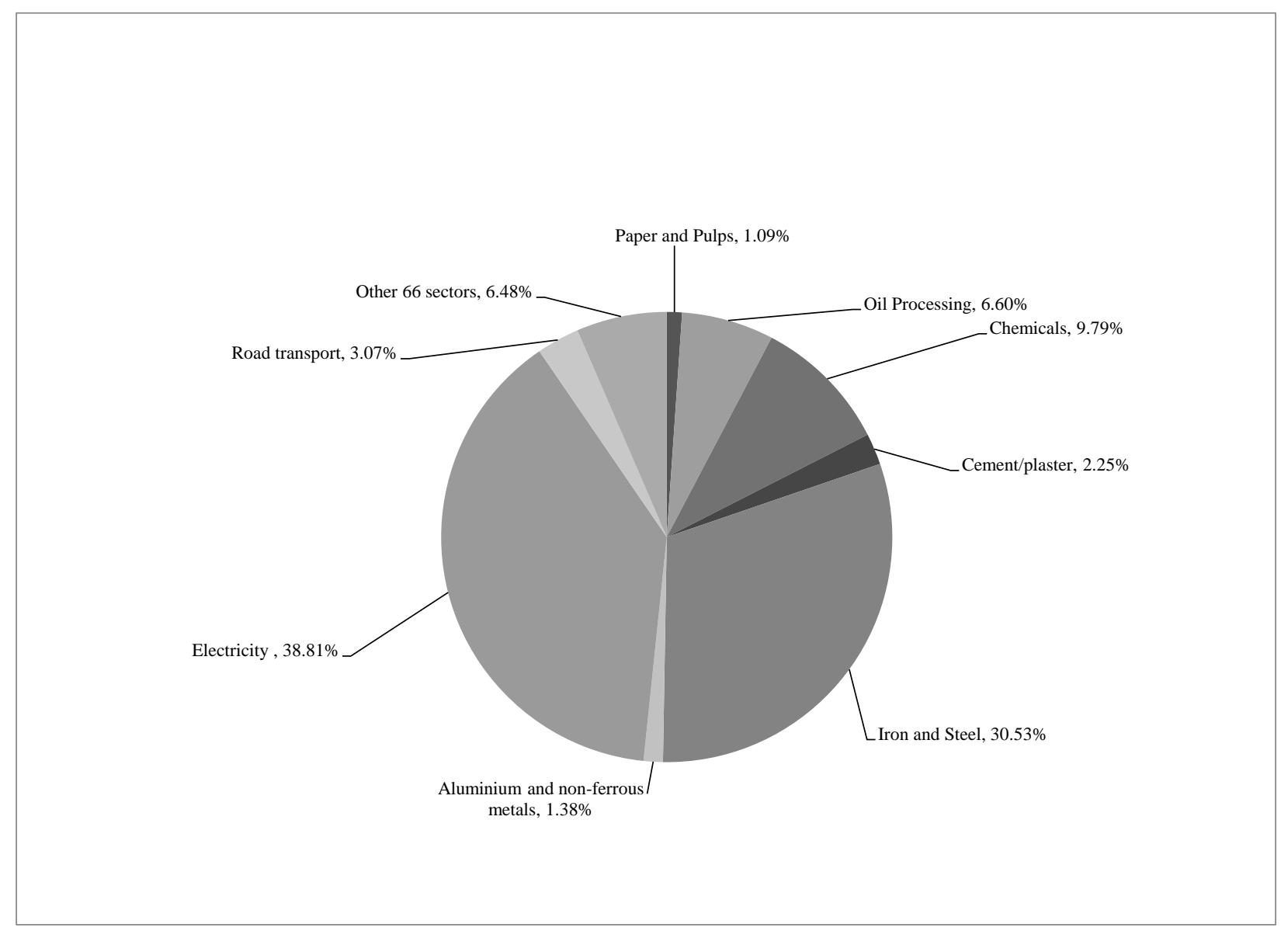


Figure 4: Region Supporting Welsh Sectoral CO2 Generation (8 sectors with highest CO2 generation to meet export demand)

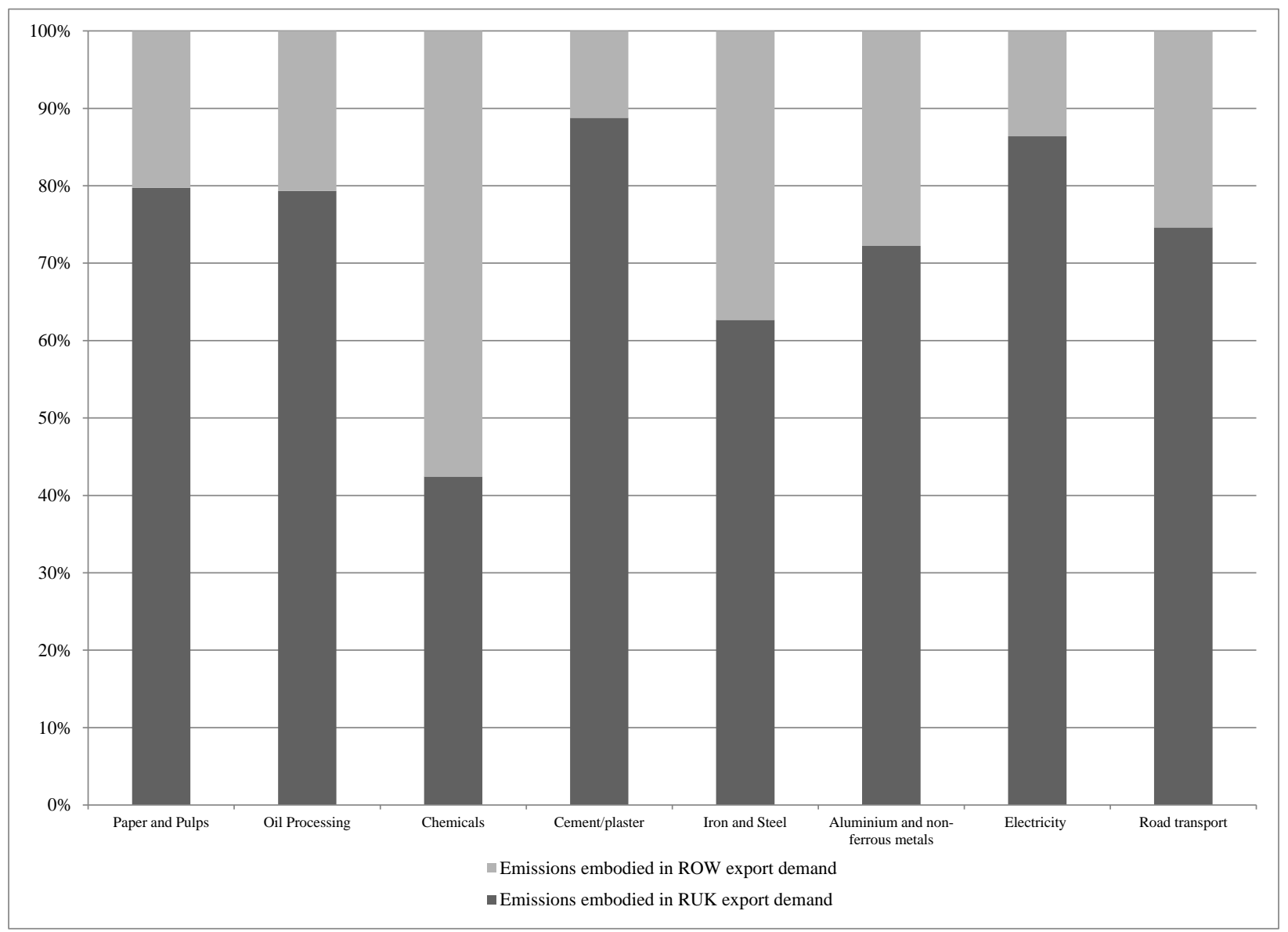


Figure 5: TELAS multipliers for sample low $\mathrm{CO} 2$ intensity sectors (tonnes of $\mathrm{CO} 2$ as carbon per $£ 1 m$ output production to meet final demand)

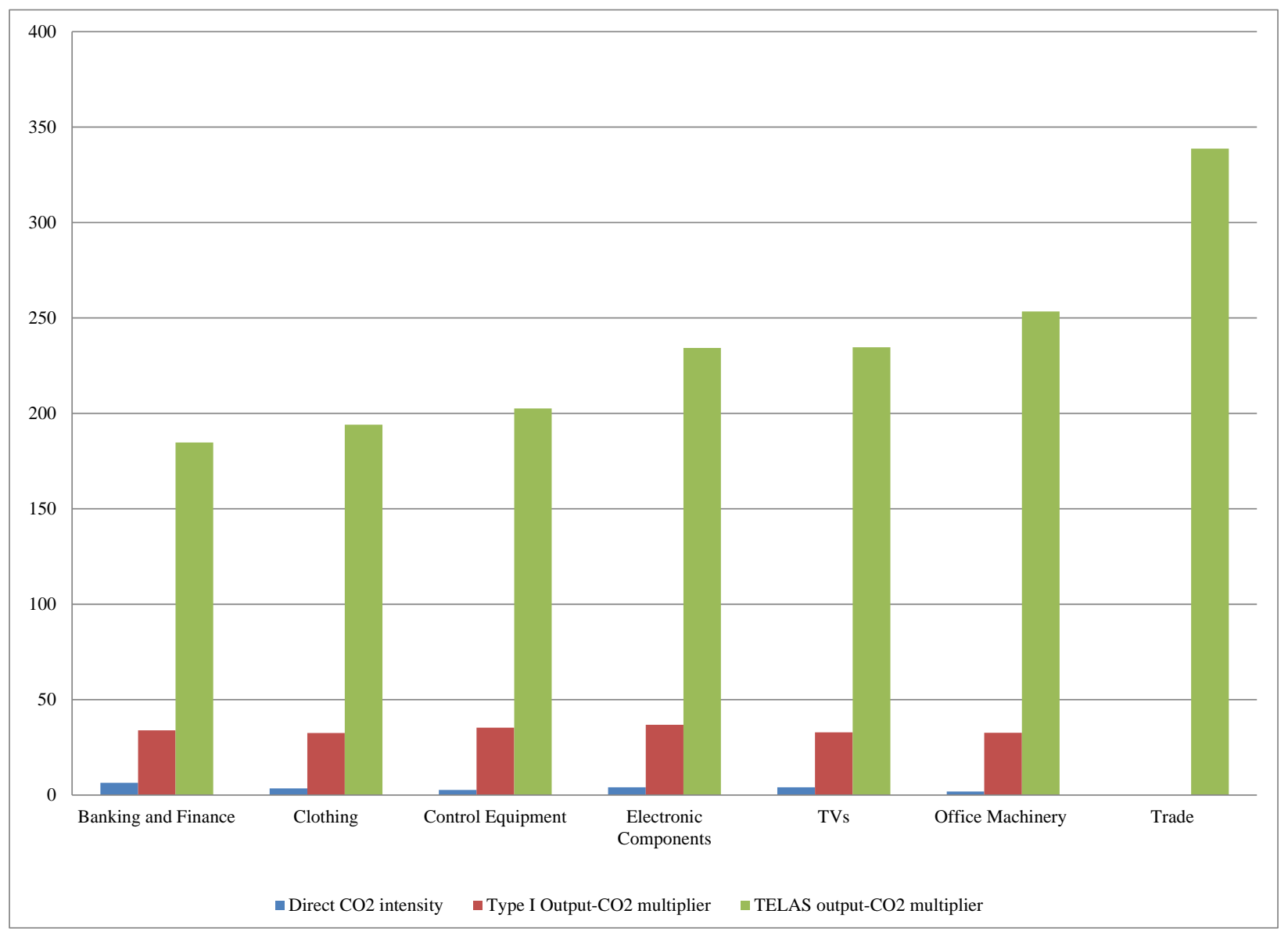




\section{Response to Editor \& Referees "Incorporating jurisdiction issues into regional carbon accounts under production and consumption accounting principles"}

\section{Response to Editor}

We have been carefully through the comments from the three referees and in what follows we explain how we have dealt with these. In particular we have now tried to place the paper in the literature and debates identified by Referee 1, and also following the comments from Referee 3 made the contribution clearer in the revised introduction, context and concluding sections. Please note that since our initial submission we have slightly adjusted our empirical analysis with more comprehensive spatial coverage in response to the first referee. Therefore, the tables and charts and text are amended where appropriate.

\section{Response to Referee 1 43/234}

We are grateful to the referee for the comments on our paper. In what follows we summarise the comment and then in italics how we have sought to deal with the comment in the revised paper.

Core issues raised by Referee 1 were related to the original paper not properly reflecting recent work published in the literature, and with the need for a better consideration of shared responsibility between producers and consumers. In what follows we show how we have integrated the suggested literature into our revision under separate heads as follows, and how we have treated with issues of shared responsibility. We have cited the majority of the additional references as suggested but have omitted some because of the need to keep to the journal word limits.

1.1 Need to examine papers in the Special Issue of Economic Systems Research including the Editorial by Wiedmann 2009 and overview by Minx et al. 2009, together with Andrew et al. 2009.

In the revised paper we have made reference to the papers in the special issue of ESR, particularly with respect to better reporting the state of the debate on the carbon footprint, and research undertaken in the UK. We have also cited this material in terms of how far inputoutput frameworks can usefully be used in estimation of carbon footprints. The text has been revised here on 44 para 3; p13 para 2. We have also referenced the contribution by Andrew et al., 2009 with respect to data issues surrounding our paper, and the extension of the framework using MRIO (see e.g. p7 para 1; p13 para 3, and p19 para 2)..

1.2 Need to cite research linking to carbon footprint analysis in the UK including Wiedmann et al. 2010, Lenzen et al. 2010. This literature was important because it reveals that research in the area has been considered by national government, and provides a comparative analysis.

We had not yet seen these papers in ESR. We have now cited the Wiedmann et al 2010 and Wiedmann et al., 2008 paper and linked this to research showing how the UK carbon footprint had gone down but been offset by a growth in emissions embodied in imports (see in revision p3 
para 2; p25, para 2). We have cited the Minx et al., (2009) review of research and the Wiedmann (2009) editorial in ESR to reveal how carbon footprint research has been funded by government and is gaining greater interest with policymakers. Please see revisions on p4 para 3 and pl3 para 2.

We have also in the revision cited the paper by Lenzen et al., 2010 but have used this in the context of the uncertainty in the underlying input-output framework (please see footnote 2 on $p 9$, and p26, para 3). The issue of uncertainty in the underlying input-output framework also was also raised by Referee 3. (See response 3.1 below).

1.3 That a formal definition of the carbon footprint had been published in Wiedmann and Minx 2007.

This reference has now been cited and linked to the development of footprint style approaches in the UK and elsewhere and the need for a proper definition. Please see p4 para 3 and footnote 1 which provides the Wiedmann and Minx 2007 definition.

1.4 Noted that a further approach has been developed, apart from consumer and producer responsibility. This has been in terms of shared responsibility (Gallego and Lenzen 2005 and Lenzen et al. 2007). Referee notes how approach combined producer and consumer responsibility (Andrew and Forgie 2008, Lennox and Andrew 2006, and Zhou 2009). Andrew and Forgie 2008 show clearly (for the case of New Zealand) how shared responsibility can offer an elegant way of combining the extreme producer and consumer responsibility principles etc.

In the revised paper we have more fully addressed the issue of shared responsibility and added the key reference in the development of the method (see p7 para 2; p8 para 2).

The main revision dealing with shared responsibility is on p23 para 3 and following. Here we argue following Peters (2008) that consumer and production accounting approaches might be considered as 2 extremes; in the discussion in the paragraph we now cite the key references including Gallego and Lenzen (2005). We note that it would be possible to apply the cited techniques to the case of Wales. However, we believe that the jurisdictional focus of the DTA analysis presented here may be extended to contribute to the shared responsibility debate by considering the relaxation of the DTA assumption. That is, we have argued that the DTA approach allows regional policymakers to focus on consumption and technology decisions that are under their jurisdiction; then any increase in the consumption accounting measure from relaxing the DTA assumption may be retained by the countries that imports are sourced from. Explaining this possibility further would be a focus of future research. Given the word constraint of the paper, we have not added a new empirical section. This decision was made on the basis that empirical extension regarding shared responsibility should be delayed until data are available to allow us to make a further contribution building on the DTA approach proposed here (see also p27 para 1 in revised conclusions on this issue).

1.5 Referee notes that given spatial focus of the journal the paper needed to provide examples of spatially explicit carbon footprint assessments. The spatially most detailed carbon footprint 
assessments today are a) a spatial breakdown by place of consumption, included in an Environmental Atlas of Australia (Centre for Integrated Sustainability Analysis and Australian Conservation Foundation 2007), and b) a spatial breakdown by place of impact (Lenzen and Peters 2010).

In line with the analysis of emissions supported by exports in Figures 2 and 4, we have introduced the rest of UK/rest of world distinction in terms of where Welsh imports come from (as well as exports to) in a revised version of Table 2. This does have interesting implications in terms of the composition of the Wales carbon trade balance and we have added to the text on pp.21-22 to reflect this. There are a number of other insertions throughout the text on the basis of this additional analysis.

We would note that in response to this comment, and one by Referee 2 (2.4), it would be interesting to a introduce a spatial breakdown within Wales. However, input-output data are simply not available to allow us to do this at the present time. We also cite the Lenzen and Peters 2009 paper (on p3 para 2) in terms of more micro jurisdiction problems and how household consumption in one place causes externalities in other parts of the domestic (and international) economy.

1.6 Original paper did not cite key references on carbon footprint and responsibility principles including Peters 2008 \& Peters and Hertwich 2008 etc.

In the revision we have cited Peters (2008)/Peters and Hertwich (2008) in connection with environmental externalities created outside state jurisdictions (p3 para 2 \& p13 para 4); the strengths and weaknesses of production and consumption based approaches to national emissions inventories ( 44 para 2); the issues that consumption based approaches may mean for policy (p5 para 2) and cited key results from Peters and Hertwich regarding the amounts of carbon embodied in global trade flows (also p5, para 2). We have also cited Peters 2008 in connection with the new discussion on shared responsibility measures and the fact that PAP and CAP approaches are two extremes (see p23, para 3 ). 


\section{Response to Referee 2 43/234}

\section{Incorporating jurisdiction issues into regional carbon accounts under production and consumption accounting principles}

We are grateful to the referee for the comments on our paper. In what follows we summarise the comment and then in italics how we have sought to deal with the comment in the revised paper.

The referee noted that the original was strongly focused on calculation method and then was losing touch with the underlying case which needed more discussion. This was context for the following points. In what follows we note the comment and then in italics how we have sought to deal with the comment in the revised paper.

2.1 Point that the 'jurisdiction' of the region was taken as a given, but with regional decision makers having limited power or influence, even on production side emissions within the territory. Discussion or a further paper might look at the reality of this particularly in key export / import sectors.

We have tried to address this particularly using some of the additional references suggested by Referees 1 and 3. At points in the revised text we have clarified that Wales is a devolved region of the UK with a legal responsibility to integrate sustainable development into its policies and practices under the Government of Wales Act (1998) (see p2 para 2; p5 para 4). We believe that in the revision at several points in the text that the 'jurisdiction' issue is a clear and present one for Welsh policy makers. We have also developed the theme of jurisdiction in response to 2.5 below, but also in the revised conclusions and discussion section where we have now highlighted the limits on the power and influence of the Welsh Assembly Government on controlling emissions produced in Wales 'close' to their own jurisdiction (see p24 para 2).

2.2 Noted that the TELAS method was less convincing, and questioned practical use in policy arena. Noted that it was hard to see how an actual trading system based on regional specialization advantage could be usefully assessed by this substitution approach.

We have attempted to make the case for inclusion of the TELAS analysis clearer and stronger in the text within the TELAS section (starting on p.14). However, we have also clarified that we regard this as an important inclusion as McGregor et al (2008) have already established TELAS as a single-region attribution technique in their publication in Ecological Economics. Therefore, and sharing their view of the potential usefulness of the approach, we feel that, given we share the single-region focus, it is appropriate to include TELAS analysis alongside our proposed DTA approach (with the latter adding value relative to the former, as noted in the referee's next comment).

2.3 Noted that the DTA approach seems clearly the more useful and common sense. However this should ideally reflect the contribution of 'policy space' i.e. if steel production changes in Wales does that reflect immediately in the global assumption? 
We have introduced discussion of the steel production case in particular on p.23 para 2. However, we would like to highlight the point made in Footnote 5 on p.18 and in the conclusions on pp.27-28 that the input output framework used here, and the technology assumptions therein (see also Footnote 2) is not really suited to modelling changes in activity. Therefore, we limit our comments to the type of accounting application used here.

2.4 Noted that the multi-level nature of the Welsh economy as a subset of the UK needed more definition and literature. In particular Wales is not a sovereign nation with fiscal identity, and so assumptions on internal supply/use and trade balance need to reflect this. Also the fact that Wales is in many ways a dual economy (metropolitan / industrial south vs rural west \& north) with many areas in high dependency \& poor internal transport.

As noted in response to point 2.1 above, we have introduced at several points in the text clarification of the legal responsibility with respect to sustainability assigned to Wales as part of UK devolution in the late 1990s. We are not sure that sovereignty is the key issue, but we note that the lack of fiscal autonomy is reflected in the construction of the Welsh IO tables (as in the case of Scotland, as another UK region). We acknowledge the referee's point that Wales is in many ways a dual economy. However, as also noted above in response to Referee 1 (1.5) a robust spatial breakdown below the Welsh regional level is not currently possible, although we accept this would be interesting.

2.5 Potential to add some case material into the paper, and showing how regional wind energy projects that supply the UK grid show up in different accounting systems.

We accept point that much of the original focused on the techniques and with rather less material relating to the Welsh case. We have developed the contextual elements of the paper in relation to the Welsh sustainable development scheme and the 'global' responsibilities that are espoused. Moreover, in the discussion around the approaches we have now integrated in material relating to recent research in Wales which has investigated the potentials for displacing imports of food with locally produced products linking to research by Kevin Morgan (see Morgan and Morley 2006), and introduced new material speaking to the steel industry and the wind generation sector (please see p16, para 2; p17, para 1, and p23, para 2). For example, we show that the wind power case is an interesting example and have added more information to the text linking to the existing discussion regarding the interregional UK trade in electricity and implications for the devolution package in the UK.

2.6 Referee notes recent history of policy initiatives and studies in Wales linking to the work and how far initiatives could be informed by the technical analysis in the paper.

In the revised paper we have now attempted to better show how the techniques discussed in the paper could inform new and existing initiatives, for example, with the sustainable development scheme of the Welsh Assembly Government in part encouraging consumer behaviour change, for example in relation to changing household behaviours in relation to travel, use of natural resources, and purchase of locally produced food (p6, para 3). We also show here how better understanding the way we account for carbon embodied in trade can impact on how a regions such as Wales can actively participate in global initiatives such as those following Kyoto. 


\section{Response to Referee 3 43/234}

\section{Incorporating jurisdiction issues into regional carbon accounts under production and consumption accounting principles}

We are grateful to the referee for the comments on our paper. In what follows we summarise the point made by the referee and then in italics how we have responded in the revised version of the paper.

3.1 Referee highlights that there is limited information regarding uncertainties associated with the Wales Input-Output framework, and with this an issue were results used to inform policy. Referee shows scale of potential problem is revealed in Lenzen et al., 2010 in ESR.

We accept this comment. There are clear issues on how far the Welsh input-output framework is accurate in describing inter-sectoral financial transactions. This links to uncertainties created by the adopted aggregation scheme and underlying values of technical coefficients etc. We have tried to address this through footnote 2 on p.9 which shows the nature of the problem and then cites Lenzen et al (2010) who provide a recent analysis of how the effects of uncertainty can be considered in the estimation of carbon footprints for the UK. In the same footnote we show that in Wales there has been no uncertainty analysis regarding developed carbon footprints, but we cite Beynon and Munday (2008) who examine the issue of general uncertainty in Welsh IO framework and impacts this has in terms of key sector analyses. We now also cite the Lenzen et al., 2010 paper in the conclusions with respect to the general difficulties of employing input output techniques for this type of analysis (see p26 para 3 ).

3.2 A paper in EST does calculate the change in emissions in the UK due to the relocation of production and this work should be recognised.

We believe here that referee was pointing towards Wiedmann et al., 2008 that showed that in the UK case that while domestic carbon emissions had gone down during the 1990s that this had actually been offset by the growth in emissions embodied in UK imports. We have now cited and explained this conclusion in p3 para 2 of the revision, and with this research also pertinent to a point we now make in the revised conclusions on the impacts of expected structural changes in the Welsh economy on emissions (see p25, para 2)..

3.3 Referee questions how far paper builds on developments of multi-regional input output models. Instead trade is endogenised within the A Matrix and a single regional assumption is adopted. The work of Glen Peters has highlighted many of the issues associated with the analysis. Additionally, there is the issue of using EEBT data or an MRIO approach. Referee then requests that we make the nature of the contribution far clearer.

We have now introduced clarification at a number of points in the text of the shortcomings of our analysis in not being able to adopt a full MRIO approach, and cited research by Peters and others in this respect (please also see response to Referee 1). However, we have also added to our emphasis that we believe the single region approach adopted to be a valuable contribution, particularly in terms of offering a 'first step' in applying IO techniques at the regional level, 
where data availability and policy understanding and acceptance of IO may be at a very early stage of development. Moreover, we reiterate our argument that the jurisdictional focus of our analysis is of particular practical interest in policy terms and this is reflected in the development of an extended single region approach. Please see for example in the revision p7, para 1 \& 2, p25, para 3; p27 para 1; and p27 footnote 6 . 